\title{
Preparation of biokit to treatment the Petrol spots in water.
}

\author{
Marwah Th. AbdulSattar ${ }^{*}$, Dr. Labeeb A. Al-Zubaidi ${ }^{*}$, Zahraa Z. Farhan ${ }^{* *}$
}

*Ministry of Science \& Technology/ Directorate of Environment and water. Baghdad. Iraq.

${ }^{* *}$ Ministry of High education \&scientific research/ University of technologies. Baghdad. Iraq.

\section{$\underline{\text { Abstract }}$}

Microorganism isolates used in plant protection were obtained from the College of Agriculture / University of Baghdad. Its purity was assured. The microbial biokit was prepared through using several unsatisfactory and environmentally friendly isolate. The bioactivity of biokit were studied in laboratory and showed susceptibility in removing contaminants. The results showed that the biomass of the isolates prior to the loading process on a medium containing crude oil as a single carbon source of $5 \mathrm{~g} / \mathrm{L}$, which indicates growth ability and efficiency in the decomposition of pollutants when increase the isolates biomass more than $3 \mathrm{~g} /$ $\mathrm{L}$, as well as the appearance of turbidity in the media compared to the control sample (media without oil), and obtained bioemulsifier with a concentration of $2.3 \mathrm{~g} / \mathrm{L}$. The chemical analysis of the samples under study was carried out using Gas Chromatography (GC) and GC-MS compared with a non-treatment (control).

The results showed the appearance of 43 topographic peaks each indicating a chemical compound in the control sample, while a number of these peaks disappeared and a space was reduced in other peaks that refers to the concentration of compounds, in the biomass sample, and reached the number of peaks in 26, indicating the efficiency of the biokit in the oil decomposition and dismantling of hydrocarbons. The increase in the number of live microorganisms and the incubation period is more than 28 days by increasing the growth intensity in the third week may be due to decomposing oil compounds and their exploitation in nutrition, where crude oil provides a source of carbon and energy for microorganism's isolates. In other results showed that the mass of crude oil was converted to a mass of gel and emulsification compared to the control sample after seven days period at a temperature of $28 \pm$ $2{ }^{\circ} \mathrm{C}$, Which is characterized by low toxicity and easy decomposition and reduces the surface tension of hydrocarbons and makes them more solubility and preparation for the dismantling of life and increase the rate of disintegration. The biokit was tested for retention in storage conditions for a period of one year.

The results showed that the viability of the biokit was effectively compared to the isolates 
at alone prior to the production of the biokit, which showed poor storage capacity. We conclude that biomass has the potential to treat hydrocarbons (oil contaminants) in the environment.

$\underline{\text { Keywords }}$ Preparation, biokit, treatment, petrol spots, water.

\section{$\underline{\text { Introduction }}$}

Oil contains many organic substances that are toxic to organisms. The most dangerous of these compounds is benzopyrene, where it is a carcinogenic that can cause the death of aquatic organisms. The toxicity of crude oil depends on its chemical and physical properties, quantity, seasons of the year and other environmental factors. Crude oil contains many other toxic compounds such as gasoline, which realest carcinogens, Ether and gasoline are toxic compounds at high concentrations, while phenol and its derivatives cause allergy when inhaled [1]. Oil floats on the surface of water forming a thin insulating layer between the water and the air. This layer spreads over a large area of the surface water (one liter of leaking oil in the river covers an area of more than 4,000 meters square of surface water) where this layer prevents the gas exchange between air and water and prevents dissolving of oxygen in the water, which affects the gas balance. The spread of oil on the surface water can affects by several factors, including the nature of oil, prevailing winds, waves and river currents and its strength. Oil compounds take a long time to get rid of them, where they are stored in the liver and fats of marine animals and these have Long-term effects that appear on the human body after several years [2].

Usually a large mortality recorded among fish as a result of occurrence of heavy crude oil, the damage remains for a long time and affects the eggs and larvae of many commercial fish, as well as the damage reach to the phytoplankton and algae, which is the primary responsible for the stabilization of energy in the marine environment (through the process of photosynthesis) which is considered a food source to marine animals directly or indirectly [3].

There are several ways to combat oil pollution, include mechanical and chemical methods, but this solution is a not substantially treatment for the problem, because the arrival of these materials to the bottom can cause the destruction of fish, snails and sandworms, Thus, this method will increase the complexity of the pollution problem. Therefore, biological treatment has emerged where it can treat the oil pollution in water by using biological decomposition. Where scientists found a number of microorganisms that have the ability to analyze oil materials and convert it to very fine drops in water. Some oil companies and specialized chemical 
laboratories in western countries have used these microorganisms extensively in treating oil stains in the seas and oceans that's caused by leaching of oil tankers [4].

A number of microorganisms Isolated and they have proved a highly efficient in the degradation of different types of hydrocarbons; their species are returned to bacteria, fungi and yeast. Biodegradation has many benefits, where it is an inexpensive method and does not require complex equipment; in addition it is a cheap method compared to other treatment methods. Microorganism are able to exploit carbon compounds in oil as a source of energy [5].

So, this study aimed to produce local kit that are safe and friendly to environmental, composed from several microorganism isolates that are capable of degraded crude oil by loading them on chemical salts to increase their efficiency in degradation and reducing oil pollution in the water, as well as increase the storage period for a relatively long time compared to the global product with low cost and ease production.

\section{Materials and Methods}

\section{1- Micro-organism that analyze hydrocarbons:}

Microorganism isolates were obtained from the Department of Plant Protection, Faculty of Agriculture/ University of Baghdad which identified by the same Department. Their purity was verified using some preliminary and biochemical tests and save until being use.

\section{2- Preparation of Culture media:}

Mineral Salt Medium (MSM) which used for growth of microorganism isolate according to [6], Modified Mineral Salt Medium (MMSM) used to encourage oil emulsion process which leads to oil degradation this media prepared according to [7], Lactose- broth used to activate the preserved isolate and check its purity [8], also Nutrient Agar was used for growth of microorganism isolate, this Nutrient Agar was made by HIMEDIA Indian company and prepared according to manufacturer instructions.

\section{3- The effectiveness of biokit:}

\section{A. preparation of biokit.}

Take the $100 \mathrm{~g}$ of $\mathrm{CaCO}_{3}$ and sterilized by oven under $160^{\circ}$ for one hour and left to cool, and then distributed in a shallow pot sterile and $100 \mathrm{ml}$ from fermentation media that prepared previously, which contain the mixed microorganism at 48 age were put. The fermentation media was prepared according to [9]. Pots that are containing $\mathrm{CaCO}_{3}$ and fermentation media was transferred to the oven at $35^{\circ}$ for 5 days to dry well then crashed under sterilize conditions. 
B. Estimation of the microorganism density in $1 \mathrm{ml}$ from the biokit.

The Microorganism density was calculated in $1 \mathrm{ml}$ according to [10].

\section{Estimation of the amount of bioemulsions produced by Microorganism}

The sample of crude oil was obtained from Kirkuk oil field and has the following characteristic in table (1).

Table (1) characteristics of Crude oil from Kirkuk oil field

\begin{tabular}{|l|l|}
\hline API $60 \mathrm{~F}^{\mathrm{o}}$ & 34.1 \\
\hline Density $15^{\circ} \mathrm{C}$ & 0.8540 \\
\hline Salt content & 0.0012 \\
\hline Water and sediment $\mathrm{Vol} \%$ & 0.05 \\
\hline
\end{tabular}

$50 \mathrm{ml}$ of sterile liquid MMSM had been vaccinated by biokit, $2 \mathrm{ml}$ of crude oil were added (tow replicate), the bottles were incubated in vibration incubator in $30^{\circ} \mathrm{Cat} 150 \mathrm{r} / \mathrm{min}$ for 27 days, then the amount of bioemulsions was calculated according to [11].

D. The a viability of the biokit for storage.

After the completion of the production process for biokit it was store in sterilize container under lab conditions, after one year the density of microorganisms was estimated in $1 \mathrm{~g}$ of the kit, in addition to study the morphological changes in crude oil degraded by the action of biokit through the incubation of the kit for one week at room temperature and recording the morphological changes.

4- Estimation of the quantitative loss of crude oil as a result of use the biokit a. by using the Non-specialized chemical methods.

Test the viability of the kit to degrade the crude oil through:

\section{Account of Biomass:}

$50 \mathrm{ml}$ of sterile liquid MSM was vaccinated by microorganism isolate that's consisting the biokit after it's grow on activated media, then added $2 \mathrm{ml}$ of crude oil (Three replicate) in 250 $\mathrm{ml}$ conical Flask (tow replicates). Flasks were placed in vibration incubator at $150 \mathrm{r} / \mathrm{min}$ in $30^{\circ}$ c for 27 days, the same procedure was done for control sample. The dry way method was used to estimate the weight of biomass. The broth put in a special tube and then expelled by Centrifuge at $12000 \mathrm{r} / \mathrm{min}$ for 30 minutes to precipitate the cells. Cells were extracted and dried at $105^{\circ} \mathrm{C}$ for 24 hours in a thermal oven [12]. 
2. Account the quantitative loss of crude oil: as a result of the growth of microorganism isolate that's consisting the biokit.

The pure isolate that's consisting the biokit that's wonted to testing their ability to degradation the crude oil was planted as mentioned in pervious section (Account of Biomass) and compared with the control sample (media without microorganism), the filtrate was collected with hexane extract after cell sedimentation then the $\mathrm{pH}$ was adjutancy to reach 2 by adding a few drops of hydrochloric acid. Hydrocarbons were extracted by adding Chloromethane solvent by using separating funnel to separate the water layer from dissolving hydrocarbons. The last layer was filtrated through filter paper that contains anhydrous sodium sulfate $\left(\mathrm{Na}_{2} \mathrm{SO}_{4}\right)$, the filtrate was collected in a clean flask, and then the filtrate was concentrated by rotary evaporator, the sample was weighted to calculate the remaining weight of hydrocarbons, the percentage of degradation rate was determined according to [13] through the equation below:

P RD CO $=$ (remainder weight of the ceude oil $)$

/(Weight of crude oil of control sample $) \times 100$

\section{b. Detection of crude oil degradation using specialized chemical methods.}

\section{Detection the degradation of crude oil by using of Gas-Chromatography GC}

The final product from the previous paragraph (Account the quantitative loss of crude oil) was taken to measure the degradation level of the crude oil components that degraded by using Gas-Chromatography device that's providing by Shimadzu Japanese company model 2014 Using a chromatographic separation column type Capillary column CPSIL5-CB, $0.4 \mathrm{ml}$ from each sample was injected in the device; the condition that's used for operate the device was as the following; the nitrogen was utilizes as Carrier gas with $25 \mathrm{ml} / \mathrm{min}$ Flow rate, temperature of the detector (FID Detector) was adjusted at $270^{\circ}$, separated column was prepared at $80^{\circ}$ as initial temperature and then programmed to raise the temperature at a rate of $5 \mathrm{c} / \mathrm{min}$ until the temperature reach to $260^{\circ}$ after $60 \mathrm{~min}$ [14]. The peak of used compounds were compared with peaks of standard material that appear at the same Retention Time, the area was calculate to estimate the Quantity of remaining hydrocarbons after microbial degradation according to following equation:

$$
\text { area }=\frac{1}{2} \text { Base } \mathrm{x} \text { height }
$$


Remaining Percentage of hydrocarbons $=($ sample area $) /($ total area $) \times 100[11]$.

\section{2- Quantitative and Qualitative analysis of the effectiveness of biokit.}

The Quantitative, Qualitative and the level of the degradation of crude oil compound before and after the activity of the biokit with 28 days of incubation was detected by utilize ofGas-Mass Chromatography device that's providing by Shimadzu Japanese company model 2014 type Agilent GC-MSD (6890N-5973) [15] at $80^{\circ}$ in 4 min with raising rate $5^{\circ}$ per minute until the temperature reach $250^{\circ}$ and maintained this temperature for 20 minutes.

\section{$\underline{\text { Results and Discussion }}$}

1- Certainty tests for the microbiological isolates that constitute biokit.

The morphological tests showed microorganism isolates that's constituting the biokit and represented by bacillary shape are; Gram positive, spores former, producing crystals protein urea, in addition to their resistance to antibiotic (Ampcillin and carbancillin) and positive to catalase test. Other test results biokit that the biokit; it are; Gram negative, motile, non-hydrogen sulfide production, glucose fermented, positive for oxidase and catalase tests and other characteristic.

2- Estimation of the density of microorganism per $1 \mathrm{~g}$ of biokit.

The density of microorganism was calculated in $1 \mathrm{~g}$ and reached $6 \times 107 \mathrm{cell} / \mathrm{g}$, which considered a very good density and indicate to; they are not affected by antibiotics (Amoxilin) ,great compatibility and affinity between the microorganism isolates in the biokit, which eventually refer to the possibility of using them in experiments of crude oil degradation.

\section{3- Estimation the amount of bioemulsions producing}

After Estimation the density of microorganism, the next step will be estimation the amount of bioemulsions produced microorganism isolates in the biokit which reach to $2.3 \mathrm{~g} / 1$ Which indicates a high production efficiency biokit for bioemulsions Compared to microorganism before loading which reach to $1 \mathrm{~g} / 1$.

4- The availability of the biokit for storage.

After one year of storage the density of biokit are calculated and reached to $4 \times 10^{6} \mathrm{cell} / \mathrm{g}$ in $1 \mathrm{~g}$, and estimate the amount of bioemulsions produced by the biokit that reached to $2.10 \mathrm{~g} / 1$ which indicate to presence of high density of microorganism and high efficiency in production of bioemulsions after the storage and the biokit are not significantly affected by the storage process. 
5- Detection of crude oil degradation by Non-specialized chemical methods.

It can be test the ability of the kit for the degradation of crude oil through calculation of quantitative loss of crude oil, which reached after the use of the biokit (after loading) 80\% Compared to the quantitative loss of crude oil before the loading process $49 \%$. In addition to calculate the biomass which is a non-specialized chemical methods where the total biomass of the kit before loading $1.25 \mathrm{~g}$, while the biomass of the kit reached after loading process 5 grams, which demonstrate the high efficiency of the effectiveness of the biokit in the degradation of crude oil and by doubling the effectiveness of the microorganism isolates before loading process.

\section{6- The effectiveness of the biokit in the degradation of oil contaminants:}

A chemical test was done for the studied samples by using the technology of Gas-Mass Chromatography (GCMS), samples where compared to un-treated a sample with biokit (control), The results showed the appearance of 43 peaks, where every peak indicating a chemical compound in the control sample (untreated crude oil). On other hand, when examining a sample treated with biokit a large number of these peaks disappeared where the number of peaks reached 26 and the area of other peaks are reduced (indicating the concentration of compounds) indicating to the efficiency of the biokit in the analysis and degradation of hydrocarbon compounds, Where many studies indicate the use of this technique to detect the degradation of oil compounds and to infer the type and concentration of these decaying compounds using chromatography technique-mass (GCMS) as mentioned in table $(2,3)$ and figures $(1,2,3)$.

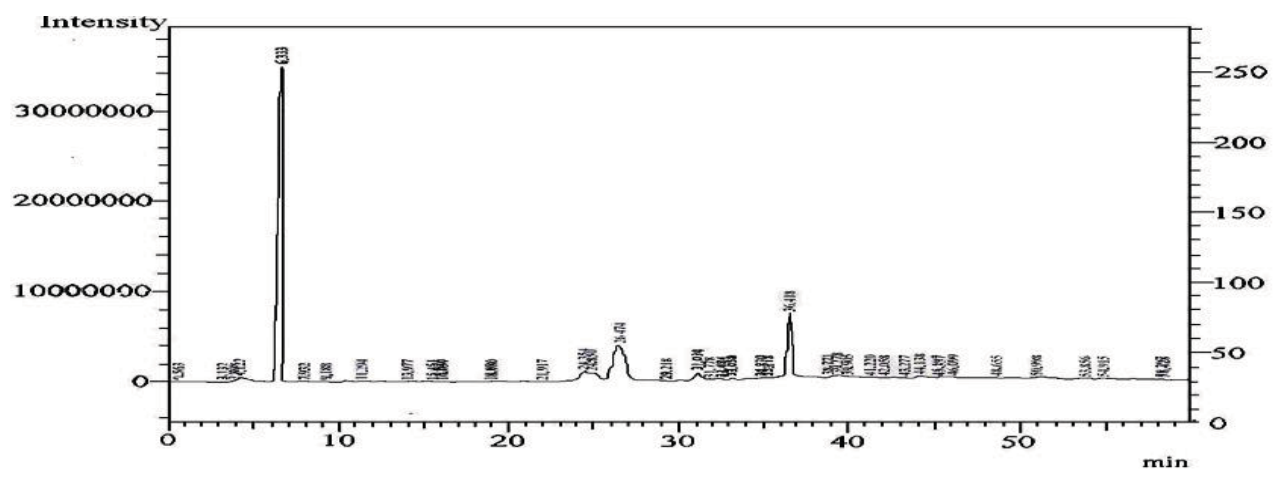

Fig. (1) Results of gas-mass chromatography (GCMS) for the control sample (untreated crude oil) where show the retention time and the peaks of the chemical compounds that's constituent it. 


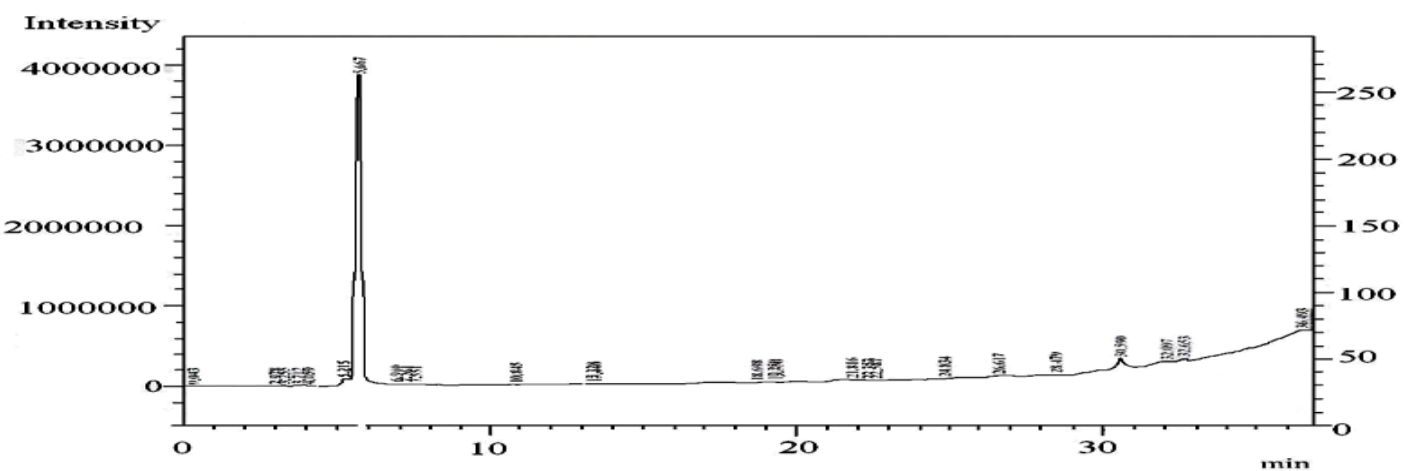

Fig. (2) The results of a gas-mass chromatography (GCMS) for a crude oil sample that's treated with biokit which show decreasing in the peak number of chemical compounds and their area.

Table (2) Results of the Gas-Mass Chromatography (GCMS) for Crude Oil Samples before and after Treatment the samples with biokit.

\begin{tabular}{|c|c|c|c|c|c|}
\hline \multicolumn{3}{|c|}{$\begin{array}{l}\text { Crude oil sample befor treatment with } \\
\text { biokit }\end{array}$} & \multicolumn{3}{|c|}{$\begin{array}{l}\text { Crude oil sample after } \\
\text { treatment with biokit }\end{array}$} \\
\hline Peak & $\begin{array}{l}\text { Ret. } \\
\text { Time }\end{array}$ & Area & Peak & $\begin{array}{l}\text { Ret. } \\
\text { Time }\end{array}$ & Area \\
\hline 1 & 0.563 & 18808 & 1 & 0.043 & 1212 \\
\hline 2 & 3.132 & 5835 & 2 & 2.978 & 1203 \\
\hline 3 & 3.808 & 134580 & 3 & 3.255 & 10853 \\
\hline 4 & 4.122 & 12371678 & 4 & 3.712 & 7180 \\
\hline 5 & 6.333 & 310450093 & 5 & 4.059 & 4244 \\
\hline 6 & 7.932 & 5118 & 6 & 5.215 & 1922879 \\
\hline 7 & 9.188 & 1517 & 7 & 5.667 & 34695432 \\
\hline 8 & 11.294 & 10668 & 8 & 6.910 & 2038 \\
\hline 9 & 13.977 & 2213 & 9 & 7.261 & 53400 \\
\hline 10 & 15.451 & 1803 & 10 & 7.551 & 12919 \\
\hline 11 & 15.825 & 2133 & 11 & 10.845 & 1012 \\
\hline 12 & 15.946 & 3016 & 12 & 13.328 & 8683 \\
\hline 13 & 16.057 & 2285 & 13 & 13.440 & 2330 \\
\hline 14 & 18.886 & 97014 & 14 & 18.698 & 1780 \\
\hline 15 & 18.980 & 4639 & 15 & 19.250 & 30285 \\
\hline
\end{tabular}




\begin{tabular}{|c|c|c|c|c|c|}
\hline 16 & 21.917 & 156114 & 16 & 19.356 & 4202 \\
\hline 17 & 24.354 & 48849407 & 17 & 21.816 & 1159549 \\
\hline 18 & 24.850 & 35435168 & 18 & 22.353 & 38286 \\
\hline 19 & 26.474 & 198956651 & 19 & 22.587 & 1934 \\
\hline 20 & 29.218 & 545744 & 20 & 24.834 & 104246 \\
\hline 21 & 31.034 & 26164157 & 21 & 26.617 & 659437 \\
\hline 22 & 31.778 & 523092 & 22 & 28.479 & 67382 \\
\hline 23 & 32.484 & 6081651 & 23 & 30.590 & 2062876 \\
\hline 24 & 33.058 & 11223506 & 24 & 32.097 & 985026 \\
\hline 25 & 34.830 & 19583428 & 25 & 32.653 & 689069 \\
\hline 26 & 35.218 & 4718906 & 26 & 36.493 & 1084836 \\
\hline 27 & 36.418 & 175276423 & & & \\
\hline 28 & 38.771 & 13703335 & & & \\
\hline 29 & 39.278 & 23285230 & & & \\
\hline 30 & 39.905 & 13834088 & & & \\
\hline 31 & 41.220 & 10681237 & & & \\
\hline 32 & 42.058 & 8476367 & & & \\
\hline 33 & 43.277 & 4271413 & & & \\
\hline 34 & 44.138 & 15004804 & & & \\
\hline 35 & 45.197 & 405091 & & & \\
\hline 36 & 45.357 & 2050375 & & & \\
\hline 37 & 46.099 & 6056145 & & & \\
\hline 38 & 48.655 & 1066996 & & & \\
\hline 39 & 50.998 & 4780445 & & & \\
\hline 40 & 53.856 & 44450 & & & \\
\hline 41 & 54.915 & 1959886 & & & \\
\hline 42 & 58.297 & 1569 & & & \\
\hline 43 & 58.428 & 3726 & & & \\
\hline
\end{tabular}




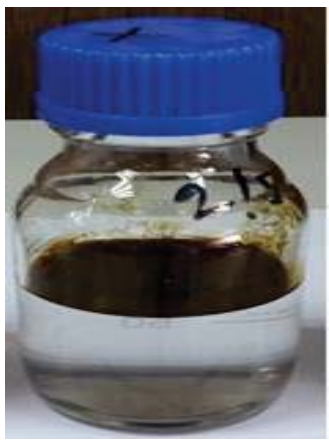

(A) Control Sample

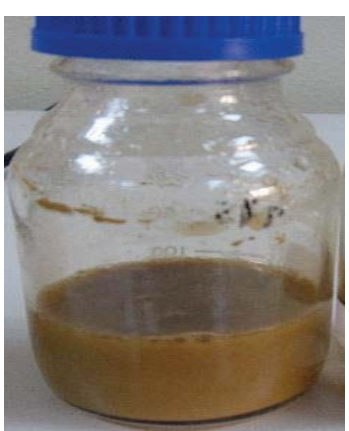

(B) Sample treated with biokit

Fig. (3) Showed the morphological changes inthe degraded crude oil by the action of biokit showed clear degradation.

Table (3) Illustrate the hydrocarbons compound degraded by the action of biokit through the results of the gas-mass chromatography.

\begin{tabular}{|c|c|}
\hline Compound name & Chemical structure \\
\hline \multicolumn{2}{|l|}{ Butanoic acid,1-1-dimethylethyl ester } \\
\hline Benzene, (2-methyloctyl) & \\
\hline $\begin{array}{l}\text { Boron, (3,3-dimethylbutyl)(n- } \\
\text { methylenemethanamine) }\end{array}$ & $\frac{1}{\frac{1}{1}=}$ \\
\hline \multicolumn{2}{|l|}{ Benzeneacetic acid ,heptyl ester } \\
\hline Oxalic acid, butyl propyl ester & (n) \\
\hline Propane,1-bromo-2,2-dimethyl & $\sum_{1,3}$ er \\
\hline \multicolumn{2}{|l|}{ Acetic acid, butoxyhydroxy, butyl ester } \\
\hline \multicolumn{2}{|l|}{ Hexan , 2,-dimethyl } \\
\hline Tert-butyl acrylate & $\mathrm{H}_{2}$ \\
\hline 1-cyclopentyl1-2,2-dimethyl-1-propanol & $\mathrm{CH}_{3}$ \\
\hline Sulfurous acid, octyl 2-propyl ester & $i^{\circ}$ \\
\hline Nonane, 3,7-dimethyl & \\
\hline
\end{tabular}




\begin{tabular}{|c|c|}
\hline Oxalic acid, isohexylneopentyl ester & 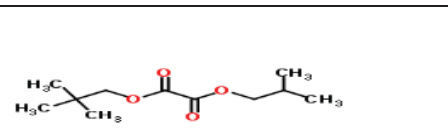 \\
\hline Sulfurous acid ,nonyl 2-propyl ester & r \\
\hline Sulfurous acid ,decyl 2-propyl ester & \\
\hline Sulfurous acid, octyl 2-propyl ester & \\
\hline Nonane ,3,7-dimethyl & \\
\hline Oxalic acid, isohexylneopentyl ester & \\
\hline $\begin{array}{l}\text { Phenol,2,6-bis(1,1-dimethylethyl)-4- } \\
\text { methyl,methylcarbamate }\end{array}$ & \\
\hline 4,6-di-tert-butyl-m-cresol & \\
\hline Butylated hydroxytoluene & \\
\hline Cyclopropanecarboxylic acid,1-hydroxy & \\
\hline Phenol,4-6di(1,1dimethylethyl)2-methyl & \\
\hline Decane,3,7-dimethyl & \\
\hline Decane,2,3,5,8-tetramethyl & \\
\hline Undecane ,3-ethyl & \\
\hline Octane,3,4,5,6-tetramethyl & $\sim_{1}^{1} 1$ \\
\hline Undecane,3,8-dimethyl & $\frac{1}{2+1}$ \\
\hline Benz[c]pyran-1,3-dione, 4,4-dimethyl & ${ }_{11}^{2}$ \\
\hline 3-phenylthiane,s,s-dioxide & 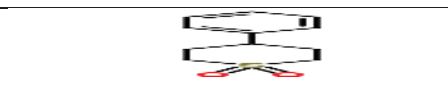 \\
\hline $\begin{array}{l}\text { 1,2,4-metheno-1H-cyclobuta[cd]pentalene- } \\
\text { 3,5-diol,octahydro }\end{array}$ & $\sum_{x \rightarrow 1} \infty$ \\
\hline Cyclohexanone, 3-phenyl & 1 \\
\hline
\end{tabular}




\begin{tabular}{|c|c|}
\hline 5-methyl-2-phenyl-2-hexenal & 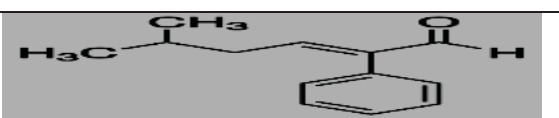 \\
\hline 1,2-Benzenedicarboxylic acid & 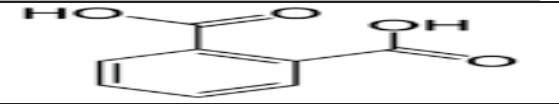 \\
\hline $\begin{array}{l}\text { 1,2-Benezenedicarboxylic acid, diisooctyl } \\
\text { ester }\end{array}$ & $\sum_{\text {II }}$ \\
\hline Bis(2-ethylhexyl)phthalate & $\pi=10$ \\
\hline
\end{tabular}

\section{Conclusion}

1- Production of a new microbial biokit that are introduced for first time as a bio factor in the analysis and degradation of hydrocarbon waste.

2- The ease of production of biokit at relatively low costs and high productivity and relatively with short periods of time.

3- The new microbial kit has effective bioactivity compared to the foreign product.

4- Production materials are locally available, friendly for environmental and public health and relatively inexpensive.

5- Storage capability is relatively high up to more than a year.

6- The potential of self-purification for the biokit that grow on oil contaminants. 


\section{References}

1. IARC (in preparation). A review of human carcinogens. F. Chemical agents and related occupations. Lyon, International Agency for Research on Cancer (IARC Monographs on the Evaluation of Carcinogenic Risks to Humans, Vol. 100) [summary in Baan R et al. (2009). A review of human carcinogens - Part F: Chemical agents and related occupations. The Lancet Oncology, 10(12):1143-1144.

2. IPCS (2004). Benzene. Geneva, World Health Organization, International Programme on Chemical Safety (International Chemical Safety Card 0015.

3. Wills, M. A. (2000). Ekologicheskaya Vahkta Sakhalina (Sakhalin Environment Watch) Ph.D. Thesis M. Inst. Petroleum.

4. Odiete, W.O. (1999). Environmental Physiology of Animals and Pollution. Published by Diversified Resources Ltd. Nigeria. Pp 157-258.

5. AMSA, Astralian Maritime Safety Authority (2004). Management and disposal of oil spill debris. Land farming of oil and oily Debris.Marine environmental protection.AMSAs Role in maritime environmental issues. PP: 1-24.

6. [6] Herman, D.C.; Zhang, Y. and Miller, R.M .(1997) Rhamnolipi (Biosurfactant) Effect On Cell Agreement and Biodegradation Of Residual hexadecaneUnder Saturated Flow Conditions.Appl.Envi-Ron. Microbiol., 63: 3622- 3627.

7. Duvnjak, Z.; Cooper, D.G. and Kosaric, N. (1982) Production Of Surfactant by Arthrobacter paraffine us ATCC 19558.Biotechnol. Bioeng.24:165-175.

8. [8] Ball, A.S. and Mc carthy, A.J. (1989) Production and Properties Of Xalanases From Actinomycetes. J. Appl. Bacteriol. 66: 439- 444.

9. Al - Rawashdeh, Muawiya Mohamed Mahmoud (2002). Studying the possibility of producing a pesticide and bio-fertilizer from Pseudomonas fluorescens and Azospirillumirakense for fungus Fusarium oxysporum sp. And improve the growth of the tomato crop. Master Thesis - college of Science - University of Kufa. Page 94.

10. Clark, F. E. (1965). Agar-plats method for total microbial (C.F. black, 1965 methods of soil analysis part 2 publisher madeson, Wisconsin, USA. pp 1572.

11. Kates, M. (1972).Techniques of lipidology. $1^{\text {st }}$ ed. Work, T. S. and Work, E. (eds.) American elsvier publishing, Co., Inc. New York.

12. Reddy, P. G.; Singh, H. D.; Pathak, M. G.; Bhagat, S.D. and Baruah, J. N. (1983) 
Isolation and Functional Characterization of Hydrocarbons Emulsifying and Solubilizing Factors Produced by a Pseudomonas species.25:287-401.

13. Teschner, M. and Wehner, H. (1985). Chromatographic investigation as on biodegraded crude oils. Chromatographia. 20: PP: 407-416.

14. Athukorala, Y.; Mazza, G. and B. D. Oomah (2009) "Extraction, purification and characterization of wax from flax (Linum usitatissimum) straw," European Journal of Lipid Science and Technology, vol. 111, no. 7, pp. 705-714.

15. Deswarte, F. E. I.; Clark, J. H.; Hardy, J. J. E. and P. M. Rose, (2006) "The fractionation of valuable wax products from wheat straw using CO2," Green Chemistry, vol. 8, no. 1, pp. 39-42. 